\title{
UNA NUEVA MIRADA SOBRE LA FUNDACIÓN DE AGUASCALIENTES
}

ANGÉLICA PEREGRINA

El Colegio de Jalisco

Jesús Gómez Serrano, La guerra chichimeca, la fundación de Aguascalientes y el exterminio de la población aborigen (1548-1620). Un ensayo de reinterpretación, Zapopan, El Colegio de Jalisco-Ayuntamiento de Aguascalientes, 2001, (Ensayos), 129 p.

$\mathrm{T}$ res líneas vertebran el trabajo de Jesús Gómez: la guerra chichimeca; la fundación de Aguascalientes y el exterminio de los aborígenes. Tres grandes temas, en efecto, pues el trabajo se propone elucidar el contexto en el cual nace la ciudad de Aguascalientes, dentro del conflicto que la colonización española enfrentaba en el norte, hasta entonces la frontera de la expansión frente a los aguerridos chichimecas. No se podría entender y comprender a cabalidad la fundación de esta ciudad, sin el acucioso compendio que Gómez Serrano hace de la guerra chichimeca, conflicto que se prolongó durante la segunda mitad del siglo XVI.

Si bien los españoles habían sometido a los mexicas en el Altiplano, y asentado en la antigua Tenochtitlán la sede del virreinato de la Nueva España un par de décadas atrás, procedieron luego a extender la campaña hacia el país de los "teuleschichimecas", emprendiendo la exploración de los territorios que se encontraban hacia la zona septentrional.

No pasaría mucho tiempo antes de que se dieran cuenta de que aquella región era muy distinta a las del centro y sur de la Nueva España. Destacaban entre otras cosas el territorio seco y una población hostil. No se encontraron ciudades o poblados es- 
tablecidos de forma permanente, no había campos de cultivos estables, ni cría de animales. Los asentamientos que encontraron eran de poca monta y los habitantes que hallaron practicaban la vida nómada y con alguna agricultura ocasional. Pronto fue reconocida la ruta del "Gran Tunal", la que según Tomás Martínez Saldaña, "se iniciaba en los confines de los dominios tarascos en la Nueva Galicia, en la actual región de los Altos de Jalisco, pasando por el Bajío en la zona central de Guanajuato hasta el Peñón Blanco, en el actual municipio de Salinas en San Luis Potosí", región que constituía la parte más importante de lo que a la postre se conocería como la "Gran Chichimeca". ${ }^{1}$

Los grupos cazadores y recolectores habitantes de la Gran Chichimeca, practicaban la caza y la recolección, estaban adaptados al medio semidesértico con una gran habilidad, conocían las estaciones de producción silvestre de la tuna, así como las

1 Tomás Martínez Saldaña. La diásporá tlaxcalteca. Colonización agrícola del norte mexicano, segunda edición, México, Gobierno del Estado de Tlaxcala, 1998, p. 37. rutas migratorias de aves y venados, recolectando además sal y otros minerales. Tal forma de vida los hacía independientes y autosuficientes en la zonas de llanos y mesetas.

Ciertamente se creía que gracias a la expedición punitiva que el virrey Antonio de Mendoza encabezó, la rebelión cazcana había sido sofocada definitivamente. Sin embargo, los ataques de los chichimecas seguían padeciéndose, mayormente en los recién descubiertos yacimientos argentíferos de Zacatecas.

El hallazgo de abundantes veneros de plata revolucionó completamente la vida económica colonial y nacieron pueblos y villas y a su vez infinidad de estancias de ganados y haciendas agrícolas. La plata se convertiría en el eje de la economía colonial. De ahí la importancia de asegurar el abastecimiento de víveres para los centros mineros y, sobre todo, el seguro traslado del metal a la ciudad de México.

Arribar a Zacatecas no era fácil, pues el camino atravesaba grandes extensiones de llanos hostiles. No bastó con armar a los mineros y convertir en reductos fortificados las explotaciones: hubo también que establecer guamiciones especiales y organizar convoyes para los viajeros y 
la conducción de la plata y las mercaderías. Como bien afirmna José Miranda, de "no haber mediado la preocupación por la defensa de tan gran riqueza, es casi seguro que los españoles no hubiesen puesto tanto empeño y tantos recursos en el avance y aseguramiento de su frontera con las tribus insumisas. El dispositivo militar del Norte y el sistema de colonización fronteriza nacen y crecen en el siglo XVI con la minería, y por la minería". ${ }^{2}$

Al lado de la minería, la ganadería se desarrolló rápidamente, pues carnes, sebos y cueros tenían gran demanda en los centros mineros. Y para organizar y regular una actividad económica que había adquirido tal auge, se recurrió a patrones y normas peninsulares, pero que sufrieron los ajustes reclamados por la realidad local. De tal manera nació la unidad territorial básica de estas comarcas: la estancia de ganados, que fue creada para el establecimiento de los rebaños cuando empezaron a formarse. Convertida pronto en condición in-

2 José Miranda, "España y Nueva España en la época de Felipe II", en Estudios nowohispanos; México, Instituto de Investigaciones Históricas de la UNAM, 1995, p. 79 . dispensable para la tenencia de hatos grandes, dio una nueva base al sistema ganadero criollo. ${ }^{3}$

La sujeción del norte fue una ardua empresa a causa de las grandes distancias y los aguerridísimos indios nómadas. En una inmensa frontera de guerra, de guerra sin cuartel, fue convertida la zona septentrional de la colonia. Ante tan dramática realidad, todo el mecanismo colonizador tuvo que ser ajustado. Fue forzoso establecer en lugares estratégicos pequeñas guarniciones o fuertes, que después se denominaron presidios, crear escoltas para las caravanas y armar a los pobladores y a los guardianes de las estancias ganaderas, y convertir pueblos e iglesias en fortines. Hubo también que repoblar y sujetar con indios amigos -de México, Tlaxcala y Michoacán-las tierras amenazadas. Fue pues la guerra chichimeca un conflicto de larga duración, que se enquistó a lo largo de la segunda mitad del siglo xvI, y que dio muchos dolores de cabeza a los gobernantes de la Nueva España, como bien lo documenta Jesús Gómez Serrano en la primera parte de su obra.

$3 \quad$ Ibid., p. 81. 
Ciertamente la política de guerra "a fuego y a sangre" puesta en práctica por los virreyes desde que se inició el conflicto, se mantuvo durante el periodo del virrey Martín Enríquez de Almanza (1.568-1580), y se complementó la campaña militar con el referido sistema de presidios, cuya mayor prioridad era mantener a salvo el tráfico del camino entre Zacatecas y México; sobre todo en el tramo de los grandes llanos -de San Miguel a las minas-, que era el más expuesto a los asaltos de los guachichiles.

El problema había alcanzado su punto más álgido, toda vez que los nómadas se habían aficionado al consumo de carne del ganado europeo, y por ende atacaban con mayor frecuencia a los rancheros; además, cuando aprendieron a montar a caballo, surgieron los más formidables adversarios, al convertirse los pueblos nómadas de la Gran Chichimeca en pueblos móviles que se desplazaban con una agilidad excepcional.

Gómez Serrano refiere los asentamientos hispanos que se establecieron en el territorio que más tarde sería jurisdicción de la villa de Aguascalientes, esto es, los presidios de Bocas y Ciénega Grande y el campamento minero de Tepezalá. Otro tanto hace respecto al nacimiento de Lagos, primera villa fundada a instancias de la audiencia de Nueva Galicia, como preámbulo de la fundación de Aguascalientes. Asimismo, da cuenta del cambio de responsable de la campaña contra los chichimecas, ahora bajo el mando del primer gobernador-presidente de la Audiencia de Nueva Galicia, el doctor Jerónimo de Orozco, muestra innegable de que se quería erradicar el conflicto y pacificar de una buena vez a la región.

Tales fueron las circunstancias en que nació la villa de Aguascalientes, justamente en un valle "pequeño y amable, prácticamente una última prolongación del Bajío, una especie de frontera con el árido y reseco norte"; sería pues el "paso de las aguas calientes" el punto que abriría para Guadalajara una carretera directa con Zacatecas y facilitaría la comunicación con Michoacán, además de constituirse, junto con Lagos y León, en una ruta alterna a las minas de Zacatecas. Su sino será el de un poblado defensivo, estrechamente vinculado con Lagos, ya que sus vecinos iban y venían entre ambas villas.

No está por demás un comentario acerca de la estrategia que la Corona española puso en práctica en aras de 
lograr la pacificación. Emulando la exitosa experiencia contra los musulmanes durante la reconquista, existe la hipótesis de que se implantó en América una política parecida, con campesinos españoles enviados a colonizar las regiones de rebelión. Tal parece que el modelo fue reproducido en la Gran Chichimeca, al poblar con gente de origen hispano, con las características dél soldado-agricultor que defiende el territorio a nombre de su rey y de éste recibe en premio las tierras y el apoyo para que las conserven, con lo que se generaba una frontera viviente y en continua avanzada. Fue pues necesario echar mano de los españoles más pobres, y por conducto de la audiencia, se ofrecía a los candidatos un solar en el sitio fundado, huertas, dos caballerías de tierra y superficies para el pastoreo de ovejas, a condición de no enajenar los bienes y no abandonar la plaza."

Gómez Serrano examina minuciosamente la polémica cédula de fundación, al aplicar el método de Foucault y "preguntar" exhaustiva-

4. José Ma. Muriá (dir.), Historia de Jalisco, t. I, Guadalajara, Gobierno de Jalisco, 1980, p. 394. mente a los documentos lo dicho y lo no dicho, con lo cual enmienda errores repetidos a lo largo de muchos años. Destaca que el nombre oficial original fue el de villa de la Ascensión y cómo varió a Asunción, llegando incluso a convertirse en patrona de su parroquia la virgen de esta última advocación. A fin de cuentas, el nombre de la villa que más se popularizó fue el de Aguascalientes y, al arribar la centuria de los mil seiscientos, ya era mejor conocida por ese nombre, tal como lo registran las visitas del obispo Alonso de la Mota y Escobar (1601), la del oidor Gaspar de la Fuente (1609) o la descripción de Domingo Lázaro de Arregui (1621).

Otro tanto se aboca Gómez Serrano acerca del nombre, origen y carácter de los fundadores. Percibo en este rubro una cierta "preocupación" por el bajo orden social al que tal parece pertenecían estos primeros pobladores. Al respecto me resulta difícil creer que pueda considerarse hoy día esto como un estigma; lo que debe juzgarse en todo caso, es el desempeño de esos actores, mas no su origen. Lo que lograron en poco más de tres décadas, entre 1575 y 1609, habla por sí solo. Una villa que a base de mucho esfuerzo subsistió y resultó importante como fortificación, que 
batalló bastante para arrancar frutos a las flacas tierras, pero sobresalió gracias a la ganadería. La preferencia por esta última se explica ante la escasez de mano de obra indígena, de tal manera que a los colonos hispanos no les quedó más remedio que trabajar con sus propias manos y, en todo caso, era preferible hacerlo a caballo, cuidando los hatos de ganado. Recuérdese que los súbditos de la Corona que vinieron al Nuevo Mundo estaban dispuestos a cualquier sacrificio por Su Majestad, excepto el de trabajar. Como quiera que haya sido, el oidor Gaspar de la Fuente mencionaba que en 1609 en esta villa había "diez estancias de ganado mayor, que en ellas se herrarán en cada un año veinte y dos mil becerros". 5

No obstante, el conflicto con los chichimecas no se había resuelto, lo que obligó al' virrey Alonso Manrique, recién llegado a la Nueva España en 1585, a cambiar las reglas del juego.

5 Jean-Pierre Berthe (ed.), "Relación de los hechos por el señor licenciado Gaspar de la Fuente, oidor...", en Sociedades en construcción. La Nueva Galicia según las visitas de oidores (1606-1616), Guadalajara, Universidad de Guadalajara-Centre Francais d'Études Mexicaines et Centraméricaines, 2000, p. 137.
Como la guerra ya se había prolongado por mucho tiempo y con un gran costo en vidas y recursos materiales, se decidió por una estrategia, como bien asienta Gómez Serrano, "de más largo plazo, menos espectacular pero más efectiva en sus resultados". Tal fue la de enviar indios "civilizados" que sirvieran de ejemplo a los indómitos chichimecas. El tiempo dio la razón al virrey, cuyas medidas llevaron la paz a esas latitudes. Sin embargo, se esclarece que los indios de la llamada "diáspora tlaxcalteca" no arribaron a esta villa.

El balance que hace Gómez Serrano de ese conflicto de larga duración, constituye la tercera y última parte del trabajo. De manera que aborda las secuelas de esa cruenta guerra que diezmó la población aborigen -llegando casi al exterminio- y la nueva etapa que Aguascalientes y su región iniciaron a partir de entonces. Etapa en la que fue creada la alcaldía mayor, como resultado de medidas administrativas tendientes a hacer más expedito el gobierno. Lapso en el que se dictaron las disposiciones del oidor Gaspar de la Fuente, en octubre de 1609 , esto es 34 años después de la fundación, con el propósito de regular la traza urbana y delimitar el perímetro citadino, así 
como ciertas condiciones de permanencia que deberían acatar los vecinos por un plazo determinado, antes de poder enajenar las propiedades, sin olvidar las prevenciones respecto a cuidar que los ganados, entonces tan abundantes y libres, no invadieran los cultivos.

Además, Gómez Serrano no omite indagar sobre el aledaño pueblo de indios de San Marcos, que nació en la segunda década del siglo XVII, y la reserva de mano de obra que a la postre representó para los españoles de la villa de Aguascalientes. En fin, es una historia que abarca los primeros y decisivos años de una ciudad que se ganaría a pulso su preeminencia. Presentado como "un ensayo de reinterpretación", este libro es el fruto más reciente de la madurez que como historiador ha alcanzado Jesús Gómez. Sin duda, el trabajo constituye una bien acabada aportación al conocimiento de la historia de la ciudad y la región de Aguascalientes. Es una obra en la que el rigor científico no redunda en un estilo complicado. Por el contrario, es un libro que se lee con facilidad e incluso con placer. 
